\title{
Adherence to treatment in patients with open-angle glaucoma and its related factors
}

\author{
Tayebeh Movahedinejad ${ }^{1}$, Mohsen Adib-Hajbaghery ${ }^{2}$
}

${ }^{1}$ M.Sc., in Nursing, Department of Medical-Surgical Nursing, Faculty of Nursing and Midwifery, Kashan University of Medical Sciences, Kashan, Iran

${ }^{2}$ Professor, Ph.D., Department of Medical-Surgical Nursing, Faculty of Nursing and Midwifery, Kashan University of Medical Sciences, Kashan, Iran

\section{Type of article: Original}

\begin{abstract}
Introduction: Lack of adherence to medical treatments typically lead to burdensome consequences such as progressive visual impairment, blindness, and disabilities. This study aimed to determine the adherence to medication in patients with open-angle glaucoma and related factors in patients referred to the Matini Ophthalmology Hospital in Kashan, Iran.

Methods: A cross-sectional study was conducted from 23 July 2015 to 20 January 2016 on all patients with open-angle glaucoma referred to the Matini Ophthalmology Hospital in Kashan, Iran. A questionnaire was used to gather data about patients' demographics and factors affecting adherence to medical treatments. The Morisky Medication Adherence Scale was used to evaluate the adherence to glaucoma medication. Results were analyzed using SPSS version 13. Descriptive statistics, chi-square, and logistic regression analysis were used.

Results: In total, 130 patients with a mean age of $55.36 \pm 15.54$ were studied. Only $34.6 \%$ of patients completely adhered to glaucoma medications. The chi-square test showed that age $(p=0.007)$, education $(p=0.01)$, life entourage $(p=0.04)$, place of residence $(p=0.06)$, average monthly income $(p=0.005)$, the interval between medical visits $(\mathrm{p}=0.007)$, problem in scheduling the medical visits $(\mathrm{p}<0.001)$, number of medications $(\mathrm{p}<0.001)$, lifelong using and side-effects of medications $(\mathrm{p}<0.001)$, answers of the physician to the patient's questions $(p<0.001)$, financial and traveling problems $(p<0.001)$, lack of skill in using eye drops $(p<0.001)$, lack of awareness of glaucoma complications and symptoms $(p<0.001)$, forgetting, fatigue, impatience, believing in uselessness of medications, and lack of support from family $(\mathrm{p}<0.001)$ were associated with patients' adherence. Logistic regression showed that $89 \%$ of variance of patients' adherence to glaucoma medications can be predicted by seven factors: problems in traveling and scheduling medical visits, the large number and side effects of medications, impatience, forgetting, and lack of skill in using eye drops.

Conclusion: About two-thirds of patients with open-angle glaucoma did not adhere to their own medications. Appropriate patient education and planning a patient follow-up strategy might positively affect the patients' adherence to glaucoma medications.
\end{abstract}

Keywords: Open-Angle Glaucoma, Adherence, Medication, Related factors

\section{Introduction}

Glaucoma is the most common cause of blindness in the world and one of the three causes of irreversible visual impairment in developed countries (1). The prevalence of glaucoma increases with age, and it is estimated that, by 2020 , the number of people with open-angle glaucoma will increase by $50 \%$ in the United States (2). The prevalence of glaucoma in people over 40 years living in Tehran, Iran, was reported as $44.1 \%$ in 2002 (3), and no recent study is available on this issue. However, in a study on the causes of vision impairment in 300 people over 40 years old referred to an eye clinic in Tabriz, Masoumi et al. reported that glaucoma was the second leading cause of visual

\section{Corresponding author:}

Professor Dr. Mohsen Adib-Hajbaghery, Department of Medical-Surgical Nursing, Faculty of Nursing and Midwifery, Kashan University of Medical Sciences, Kashan, Iran.

Tel: +98.9133630272, Email: adib1344@yahoo.com

Received: May 31, 2016, Accepted: August 28, 2016, Published: September 2016

iThenticate screening: August 28, 2016, English editing: September 04, 2016, Quality control: September 09, 2016

(C) 2016 The Authors. This is an open access article under the terms of the Creative Commons Attribution-NonCommercialNoDerivs License, which permits use and distribution in any medium, provided the original work is properly cited, the use is non-commercial and no modifications or adaptations are made. 
impairment (4). At present, there is no specific drug to treat nerve damage from glaucoma, and the optic nerve can only be preserved through controlling the intraocular pressure (IOP). The IOP can be controlled by topical, oral, or intravenous medications (5). Patients' noncompliance with medical treatments would result in irreversible visual damages such as progressive optic nerve damage and visual field loss secondary to increased IOP. A study in Greece showed that almost $10 \%$ of visual field defects are caused by patients' nonadherence to prescribed treatments (6). Adherence to treatment is defined as "patient's compliance with medical recommendations offered by healthcare providers" (7). Patients' lack of awareness of the nature of the disease and the risks of failure to comply with treatment, as well as poor performance in implementing medical advices, are the two factors hindering proper treatment in chronic diseases such as glaucoma. Evidence showed that effective medical treatment of glaucoma can prevent up to $50 \%$ of blindness (8), while failure to comply with intraocular hypertension therapy is a serious factor in the progression of glaucoma (5). Studies reported different levels of adherence to treatment. Schwartz and Quigley in a systematic review reported that $24 \%-98 \%$ of patients in different studies are adhering to prescribed treatments (9). A number of causes such as lack of understanding of the nature of the illness and being long-term (6), lack of obvious symptoms in its early stages $(10)$, and financial problems $(11,12)$, were cited for patients' lack of adherence to treatment. Moreover, patients' individual characteristics such as age, sex, race, education, and marital status might affect their adherence to treatment $(11,12)$. Only one study on the adherence to glaucoma treatment has been released from Iran, which reported that one-third of patients do not follow the medical advice due to factors such as low education level, difficulties in using the prescribed medications, and lack of awareness of the disease complications (13). However, a study in Ethiopia reported that $66 \%$ of patients did not adhere to the treatment and the level of adherence was significantly associated with factors such as age, disease stage, intervals between medical visits, and patients' financial status. However, no relationship was found between adherence and marital status, education level and gender (11). In contrast, in a study on 126 patients with glaucoma, Ung et al. reported that, apart from the severity of the disease, none of the individual variables such as age, sex, race, education level, disease duration, and number of drugs used were associated with adherence to treatment (12). Consistently, Welge-Lussen, Weise, and $\mathrm{Yu}$ could not find a significant relationship between adherence to glaucoma topical eye drops and patients' age, sex, and education level (14). A study on the relationship between intensity of side effects of topical glaucoma medication and its influence on adherence behavior in patients could not detect any significant influence of intensity of side effects on patients' adherence behavior (15). In another study, race was the most powerful predictor of adherence to therapy; thus the white race adhered to glaucoma medications three times greater than non-white races (16). Lack of adherence to medical advices typically lead to burdensome consequences such as progressive visual impairment, increased costs due to increased need for surgical treatments, blindness, and disabilities. Considering the crucial importance of adherence to medications in patients with glaucoma, and lack of studies in this regard in Iran, identifying the causes of nonadherence can help a healthcare team to improve care plans and preserve patients' vision, The general objective of this research was to determine the adherence to medication in patients with open-angle glaucoma and its related factors in patients referred to Matini Ophthalmology Hospital in Kashan, Iran.

\section{Material and Methods \\ 2.1. Research design}

A cross-sectional prospective study was conducted on all patients with open-angle glaucoma referred to the Matini Ophthalmology Hospital in Kashan, Iran. The study was undertaken from 23 July 2015 to 20 January 2016. The inclusion criteria were having a medical diagnosis of open-angle glaucoma at least for six months and being under medical treatment. During the study, 130 patients with inclusion criteria were referred to the aforementioned clinic for their routine medical visits or periodic diagnostic tests. After identifying the patients and explaining the study objectives, and, using the study instrument, all patients were interviewed in a private and quiet room in the ophthalmology clinic.

\subsection{Sampling}

In order to calculate the sample size, registered data concerning the number of patients with open-angle glaucoma in the same period of the previous year was obtained from the archives of the Matini Ophthalmology Hospital. Based on the recorded data, 120 patients with open-angle glaucoma have been referred at the same period of the previous year (i.e., an average of 0.83 patients per working day). Then, the number of samples was estimated to be about 120 patients. Then, a consecutive sampling method was used and finally 130 patients with inclusion criteria were referred and recruited during the present study. 


\subsection{Measurement tool}

The study instrument comprised five parts (Table 1). The first part included questions of the demographics such as age, gender, marital status, education level, occupation, life entourage (i.e., living with children, spouse, children and spouse, others, or living alone), living location, insurance coverage, and average monthly income. The second part included questions related to disease (i.e., disease severity, time of onset, and interval between medical visits). The third part contained items related to the treatment (i.e., problem in scheduling times for medical visits, large number of the medications, necessity for lifelong usage of glaucoma medications, simultaneous usage of other medication due to co-morbidities, side effects of glaucoma medications, and the ophthalmologist's lack of time to answer patient's questions). The fourth part included questions on patient's own problems that might affect his/her adherence (i.e., financial problems in purchasing medications, difficulties in travel to and from the doctor's office, forgetting the medications, having difficulties in using eye drops, lack of awareness of disease symptoms and complications, impatience for presentation of the drugs' effects, believing in uselessness of medications in controlling the disease, and lack of support from family). All questions in the second to the fourth part of the instrument asked about having or not having the problem. The content validity of the instrument was assessed by five ophthalmologists and three nursing faculty members at Kashan University of Medical Sciences. The reliability of the instrument was also confirmed through inter-rater reliability. To this end, the second author and a trained research assistant implemented the instrument to 10 patients separately (with an hour interval). Then, the correlation coefficient of responses was calculated as 0.86. The Morisky Medication Adherence Scale (MMAS) was used as the fifth part of the instrument to evaluate the adherence to the glaucoma medication. The MMAS is composed of four questions that are answered as yes $(=1)$ or no $(=0)$. The total score ranges from zero to four. Then, a total score of zero is considered as high level adherence while scores 1-2 and 3-4 are considered as moderate and weak adherence, respectively (17). However, in this study the score zero was considered as complete adherence, while scores 1-4 are considered as non-adherence. The original English version of the MMAS was translated into Farsi language by a bilanguage person and then was back-translated to English by another bi-language person and then compared with the original version that was perfectly matched. The content validity of Farsi version of MMAS was confirmed by five ophthalmologists and three professors in nursing. The reliability of this tool also was assessed through inter-rater reliability. For this purpose, the MMAS was administered to 10 patients, each patient for two times with a week interval. Then, the Spearman correlation coefficient of the two set of scores were calculated as 0.95.

Table 1. Study instrument

\begin{tabular}{|l|l|}
\hline $\begin{array}{l}\text { Questionnaire } \\
\text { parts }\end{array}$ & Variables \\
\hline $\begin{array}{l}\text { Demographic } \\
\text { information }\end{array}$ & $\begin{array}{l}\text { Age, gender, marital status, education level, job, life entourage, place of residence, place of } \\
\text { residence, average monthly income }\end{array}$ \\
\hline $\begin{array}{l}\text { Factors related to } \\
\text { disease }\end{array}$ & Stage of the disease, interval between medical visits, time of onset \\
\hline $\begin{array}{l}\text { Treatment } \\
\text { Problems }\end{array}$ & $\begin{array}{l}\text { Scheduling times for medical visits, large number of medications, lifelong using of glaucoma } \\
\text { medications, drugs for other diseases, side effects of glaucoma medications, answers of the } \\
\text { ophthalmologist to the patient's questions }\end{array}$ \\
\hline $\begin{array}{l}\text { Patients' } \\
\text { Individual } \\
\text { Problems }\end{array}$ & $\begin{array}{l}\text { Financial problems, travel to and from the doctor's office, forgetting the medications, using } \\
\text { eye drops, lack of awareness of glaucoma symptoms, lack of awareness of glaucoma } \\
\text { complications, fatigue and impatience for using drugs, believing in uselessness of } \\
\text { medications, lack of support from family }\end{array}$ \\
\hline MMAS* & $\begin{array}{l}\text { 1) Do you ever forget to take your medicine? 2) Are you careless at times about taking your } \\
\text { medicine? 3) When you feel better do you sometimes stop taking your medicine? 4) } \\
\text { Sometimes if you feel worse when you take your medicine, do you stop taking it? }\end{array}$ \\
\hline
\end{tabular}

* Fifth part adopted from Morisky medication adherence scale (17).

\subsection{Data collection and ethics}

All parts of the instrument were completed through individual interviews except for the question related to the disease severity that was completed by an ophthalmologist according to the American Academy of ophthalmology guideline (18). The Institutional Review Board and Research Ethics Committee of Kashan University of Medical Sciences and Healthcare Services, Kashan, Iran, approved the study (ref. no: IR.KAUMS.REC.1394.71). Required permissions also were received from authorities in Matini Hospital. All subjects were briefed about the study objectives, signed a written informed consent, and were assured of the voluntary participation, confidentiality of their personal information, and absence of any constraint to participate in the study. 


\subsection{Statistical analyses}

Statistical analysis was conducted using SPSS software, version 13. Descriptive statistics (i.e., frequencies, percentage, mean and standard deviation) were calculated for all variables. A chi-square test was used to examine the relationship between levels of adherence and other variables. Logistic regression was used to identify the predictors of adherence to glaucoma medications. The significance level was set at $(p<0.05)$ in all tests.

\section{Results}

During the study, 130 patients with a mean age of $55.36 \pm 15.54$ years and mean glaucoma duration of $94.06 \pm$ 74.50 months were referred to the ophthalmology clinic of Matini Hospital. Patients' demographic characteristics are summarized in Table 2 . Among the total patients, $34.6 \%$ completely adhered to their glaucoma medications while $65.4 \%$ did not fully adhere to their medications. Patients' adherence to medication was significantly associated with their age $(p=0.007)$, education level $(p=0.01)$, and monthly income $(p=0.005)$. However, it was not significantly in relationship with patients' gender $(\mathrm{p}=0.95)$, marital status $(\mathrm{p}=0.76)$, job $(\mathrm{p}=0.44)$, insurance coverage $(\mathrm{p}=0.31)$, and place of residence $(\mathrm{p}=0.06)$ (Table 2$)$. Among all patients, $62.30 \%$ had moderate or severe glaucoma. However, no significant relationship was found between stage of disease and the patients' adherence $(p=$ $0.55)$.

Table 2. Demographic data of patients with open-angle glaucoma referred to Matini Ophthalmology Center

\begin{tabular}{|c|c|c|c|c|c|}
\hline \multirow{2}{*}{\multicolumn{2}{|c|}{ Demographics characteristics }} & \multicolumn{4}{|l|}{ Adherence } \\
\hline & & Yes, $n(\%)$ & No, $n(\%)$ & Total, $n(\%)$ & $p$-value \\
\hline \multirow[t]{3}{*}{ Age (year) } & $\leq 30$ & $3(33.3)$ & $6(66.7)$ & $9(100)$ & \multirow[t]{3}{*}{0.007} \\
\hline & $31-50$ & $22(53.7)$ & $19(46.3)$ & $41(100)$ & \\
\hline & $\geq 51$ & $20(25)$ & $60(75)$ & $80(100)$ & \\
\hline \multirow[t]{2}{*}{ Gender } & Female & $23(34.8)$ & $43(65.2)$ & $66(100)$ & \multirow[t]{2}{*}{0.95} \\
\hline & Male & $22(34.4)$ & $42(65.6)$ & $64(100)$ & \\
\hline \multirow[t]{2}{*}{ Marital status } & Married & $40(35.1)$ & $74(64.9)$ & $114(100)$ & \multirow[t]{2}{*}{0.76} \\
\hline & Single & $5(31.2)$ & $11(68.8)$ & $16(100)$ & \\
\hline \multirow[t]{2}{*}{ Education level } & Illiterate & $4(14.3)$ & $24(85.7)$ & $28(100)$ & \multirow[t]{2}{*}{0.01} \\
\hline & Literate & $41(40.2)$ & $61(59.8)$ & $102(100)$ & \\
\hline \multirow[t]{5}{*}{ Job } & Retired & $12(37.7)$ & $21(62.3)$ & $33(100)$ & \multirow[t]{5}{*}{0.44} \\
\hline & Housewife & $17(30.4)$ & $39(69.6)$ & $56(100)$ & \\
\hline & Employee & $8(57.1)$ & $6(42.9)$ & $14(100)$ & \\
\hline & Students & $1(25)$ & $3(75)$ & $4(100)$ & \\
\hline & Other & $7(30.4)$ & $16(69.6)$ & $23(100)$ & \\
\hline \multirow[t]{5}{*}{ Life entourage } & With spouse & $5(17.2)$ & $24(82.8)$ & $29(100)$ & \multirow[t]{5}{*}{0.04} \\
\hline & with children & $2(18.2)$ & $9(81.8)$ & $11(100)$ & \\
\hline & With spouse and children & $33(45.8)$ & $39(54.2)$ & $72(100)$ & \\
\hline & alone & $1(20)$ & $4(80)$ & $5(100)$ & \\
\hline & Others & $4(30.8)$ & $9(69.2)$ & $13(100)$ & \\
\hline \multirow[t]{2}{*}{ Place of residence } & City & $43(37.4)$ & $72(62.6)$ & $115(100)$ & \multirow[t]{2}{*}{0.06} \\
\hline & Village & $2(13.3)$ & $13(86.7)$ & $15(100)$ & \\
\hline \multirow[t]{2}{*}{ Insurance coverage } & Yes & $44(34.4)$ & $84(65.6)$ & $128(100)$ & \multirow[t]{2}{*}{0.31} \\
\hline & No & $1(50)$ & $1(50)$ & $2(100)$ & \\
\hline \multirow[t]{3}{*}{ Average monthly income (USD) } & $<333$ & $13(22.4)$ & $45(77.6)$ & $58(100)$ & \multirow[t]{3}{*}{0.005} \\
\hline & $333-1000$ & $23(39)$ & $36(61)$ & $59(100)$ & \\
\hline & $>1000$ & $9(68.9)$ & $4(31.1)$ & $13(100)$ & \\
\hline
\end{tabular}

While $48.3 \%$ of patients with disease duration of $6-24$ months showed complete adherence to medications, $71.6 \%$ of those with disease duration more than 60 months did not adhere to medications. However, adherence to medications was not significantly different among patients with different disease duration. Most patients (57.69\%) had a followup visit to the ophthalmologist at least every six months, and a significant relationship was observed between intervals of medical visits and adherence to medications $(\mathrm{p}=0.007)$ (Table 3$)$. Lack of knowledge about the disease, forgetting the medications, difficulties in travel to and from the doctor's office, impatience for presentation of the drugs' effects, and necessity for lifelong using of glaucoma medications were among the most common individual and disease-related factors affecting the patients adherence to treatments (Tables 4 and 5). 
http://www.ephysician.ir

Table 3. Factors related to disease in patients with open-angle glaucoma referred to Matini Ophthalmology Center

\begin{tabular}{|c|c|c|c|c|c|}
\hline \multirow{2}{*}{\multicolumn{2}{|c|}{ Factors Related To Disease }} & \multicolumn{4}{|l|}{ Adherence } \\
\hline & & Yes, $n(\%)$ & No, $n(\%)$ & Total, $n(\%)$ & $p$-value \\
\hline \multirow[t]{4}{*}{ Stage of disease } & Elevated IOP & $5(35.7)$ & $9(64.3)$ & $14(100)$ & \multirow[t]{4}{*}{0.55} \\
\hline & Mild & $14(40)$ & $21(60)$ & $35(100)$ & \\
\hline & Moderate & $16(38.1)$ & $26(61.9)$ & $42(100)$ & \\
\hline & Severe & $10(25.6)$ & $29(74.4)$ & $39(100)$ & \\
\hline \multirow[t]{4}{*}{ Interval between medical visits } & $\leq$ Every 6 months & $34(45.3)$ & $41(54.7)$ & $75(100)$ & \multirow[t]{4}{*}{0.007} \\
\hline & Every $7-12$ months & $8(25)$ & $24(75)$ & $32(100)$ & \\
\hline & Every $13-24$ months & $3(23.1)$ & $10(76.9)$ & $13(100)$ & \\
\hline & $\geq$ Every 2 years & $0(0)$ & $10(100)$ & $10(100)$ & \\
\hline \multirow[t]{3}{*}{ Time of onset (months) } & $6-24$ & $14(48.3)$ & $15(51.7)$ & $29(100)$ & \multirow[t]{3}{*}{0.15} \\
\hline & $25-60$ & $10(37)$ & $17(63)$ & $27(100)$ & \\
\hline & $\geq 61$ & $21(28.4)$ & $53(71.6)$ & $74(100)$ & \\
\hline
\end{tabular}

Table 4. Problems related to treatment in patients with open-angle glaucoma referred to Matini Ophthalmology Center

\begin{tabular}{|c|c|c|c|c|c|}
\hline \multirow{2}{*}{\multicolumn{2}{|c|}{ Treatment Problems }} & \multicolumn{4}{|l|}{ Adherence } \\
\hline & & Yes, $n(\%)$ & No, $n(\%)$ & Total, $n(\%)$ & $p$-value \\
\hline \multirow[t]{2}{*}{ Problem in scheduling times for medical visits } & Yes & $3(5.3)$ & $54(94.7)$ & $57(100)$ & \multirow[t]{2}{*}{$<0.001$} \\
\hline & No & $42(57.5)$ & $31(42.5)$ & $73(100)$ & \\
\hline \multirow[t]{2}{*}{ Large number of medications } & Yes & $5(10.4)$ & $43(89.6)$ & $48(100)$ & \multirow[t]{2}{*}{$<0.001$} \\
\hline & No & $40(48.8)$ & $42(51.2)$ & $82(100)$ & \\
\hline \multirow[t]{2}{*}{ Lifelong using of glaucoma medications } & Yes & $6(9.8)$ & $55(90.2)$ & $61(100)$ & \multirow[t]{2}{*}{$<0.001$} \\
\hline & No & $39(56.5)$ & $30(43.5)$ & $69(100)$ & \\
\hline \multirow[t]{2}{*}{ Drugs for other diseases } & Yes & $6(10.5)$ & $51(89.5)$ & $57(100)$ & \multirow[t]{2}{*}{$<0.001$} \\
\hline & No & $39(53.4)$ & $34(46.6)$ & $73(100)$ & \\
\hline \multirow[t]{2}{*}{ Side effects of glaucoma medications } & Yes & $2(4.9)$ & $39(95.1)$ & $41(100)$ & \multirow[t]{2}{*}{$<0.001$} \\
\hline & No & $43(48.3)$ & $46(51.7)$ & $89(100)$ & \\
\hline \multirow{2}{*}{$\begin{array}{l}\text { Answering to the patient questions by the } \\
\text { ophthalmologist }\end{array}$} & Yes & $2(8)$ & $23(92)$ & $25(100)$ & \multirow[t]{2}{*}{$<0.001$} \\
\hline & No & $41(43)$ & $62(59)$ & $105(100)$ & \\
\hline
\end{tabular}

Table 5. Individual problems related to treatment in patients with open-angle glaucoma referred to Matini Ophthalmology Center *

\begin{tabular}{|c|c|c|c|c|c|}
\hline \multirow{2}{*}{\multicolumn{2}{|c|}{ Individual Problems }} & \multirow{2}{*}{\multicolumn{4}{|c|}{ Adherence }} \\
\hline & & & & & \\
\hline \multirow{2}{*}{ Financial problems } & Yes & $\frac{\text { Yes, } n(\%)}{7(12.3)}$ & $\begin{array}{l}\text { No, } n(\%) \\
50(87.7)\end{array}$ & $\frac{\text { Total, } n(\%)}{57(100)}$ & $\frac{p \text {-value }}{<0.001}$ \\
\hline & No & $37(52.1)$ & $35(47.9)$ & $73(100)$ & \\
\hline \multirow[t]{2}{*}{ Travel to and from the doctor's office } & Yes & $8(11.1)$ & $64(88.9)$ & $72(100)$ & \multirow[t]{2}{*}{$<0.001$} \\
\hline & No & $37(63.8)$ & $21(36.2)$ & $58(100)$ & \\
\hline \multirow[t]{2}{*}{ Forgetting the medications } & Yes & $6(7.7)$ & $72(92.3)$ & $78(100)$ & \multirow[t]{2}{*}{$<0.001$} \\
\hline & No & $39(75)$ & $13(25)$ & $52(100)$ & \\
\hline \multirow[t]{2}{*}{ Problem in using eye drops } & Yes & $2(3.7)$ & $52(96.3)$ & $54(100)$ & \multirow[t]{2}{*}{$<0.001$} \\
\hline & No & $43(56.6)$ & $33(43.4)$ & $76(100)$ & \\
\hline \multirow[t]{2}{*}{ Lack of awareness of glaucoma symptoms } & Yes & $11(13.3)$ & $72(86.7)$ & $83(100)$ & \multirow[t]{2}{*}{$<0.001$} \\
\hline & No & $34(72.3)$ & $13(27.7)$ & $47(100)$ & \\
\hline \multirow[t]{2}{*}{ Lack of awareness of glaucoma complications } & Yes & $9(14.5)$ & $53(85.5)$ & $62(100)$ & \multirow[t]{2}{*}{$<0.001$} \\
\hline & No & $36(52.9)$ & $32(47.1)$ & $68(100)$ & \\
\hline \multirow[t]{2}{*}{ Fatigue and impatience for using drugs } & Yes & $5(7.7)$ & $60(92.3)$ & $65(100)$ & \multirow[t]{2}{*}{$<0.001$} \\
\hline & No & $40(61.5)$ & $25(38.5)$ & $65(100)$ & \\
\hline \multirow[t]{2}{*}{ Believing in uselessness of medications } & Yes & $1(2.4)$ & $40(97.6)$ & $41(100)$ & \multirow[t]{2}{*}{$<0.001$} \\
\hline & No & $44(49.4)$ & $45(50.6)$ & $89(100)$ & \\
\hline \multirow[t]{2}{*}{ Lack of support from family } & Yes & $1(2.7)$ & $36(97.3)$ & $37(100)$ & \multirow[t]{2}{*}{$<0.001$} \\
\hline & No & $44(47.3)$ & $49(52.7)$ & $93(100)$ & \\
\hline
\end{tabular}


Among all individual and disease-related variables entered into the logistic regression model, a large number of medications, problem in scheduling times for medical visits, side-effects of glaucoma medications, difficulties in travel to and from the doctor's office, forgetting the medications, having difficulties in using eye drops, and impatience for presentation of the drugs' effects could significantly predict the patients' level of adherence to medications (Table 6).

Table 6. Factors affecting adherence to glaucoma medications in logistic regression model

\begin{tabular}{|l|l|l|l|l|l|l|}
\hline Variables & B & S.E. & Wald & df & p-value & Exp (B) \\
\hline Large number of medications & 3.455 & 1.365 & 6.401 & 1 & 0.011 & 31.644 \\
\hline Forgetting the medications & 4.276 & 1.510 & 8.019 & 1 & 0.005 & 71.967 \\
\hline Using eye drops & 5.566 & 1.923 & 8.376 & 1 & 0.004 & 261.389 \\
\hline Side-effects of glaucoma medications & -6.018 & 1.871 & 10.346 & 1 & 0.001 & 0.002 \\
\hline Fatigue and impatience for using drugs & 2.929 & 1.349 & 4.717 & 1 & 0.030 & 18.714 \\
\hline Scheduling times for medical visits & 4.570 & 1.473 & 9.633 & 1 & 0.002 & 96.582 \\
\hline Difficulties in travel to and from the doctor's office & 4.540 & 1.512 & 9.014 & 1 & 0.003 & 93.677 \\
\hline
\end{tabular}

\section{Discussion}

About two-thirds of patients in the present study did not adhere to their own medication. A systematic review has reported that rates of adherence in different studies is $24 \%-98 \%$ (9). Consistent with our finding, Tamrat and Gessesse also have reported that $67.5 \%$ of Ethiopian glaucoma patients did not adhere to prescribed medications (11). Newman et al. (19) and Mowatt et al. (20) have also reported that only about a third of patients with glaucoma fully adhere to their own medical plan. Findings of the present study along with earlier studies show that patients with glaucoma do not adhere to medical advices. This is a critically alarming sign not only for physicians, but also for healthcare authorities to design and implement appropriate strategies to enhance the medication adherence in patients with glaucoma. More than $61 \%$ of patients in the current study were over the age 51 , and a significant relationship was found between age and adherence. This finding was consistent with results of Abu Hussein et al. (21) who instigated factors affecting adherence to glaucoma topical medications in Egyptian patients and reported that age over 50 is an important predictor for nonadherence. However, Mowatt et al. in an eye clinic in Jamaican (20) and Cook et al. (22) in a multisite study reported that patients' demographic variables such as age, gender, and occupation cannot significantly predict their adherence to glaucoma treatment. Although the controversies between studies might be attributed to the characteristics of the populations studied, it seems that, with increase in age, patients are confronted with problems such as hand tremor and amnesia that might negatively affect their capability in using topical eye medications and consequently would decrease their adherence. In the present study, a significant relationship was observed between patients' education level and their adherence to medications. This finding was in line with results of Abu Hussein et al. (21) in a study on Egyptian patients with glaucoma. However, Mowatt et al. (20) and Cook et al. (22) could not find any significant relationship between patients' demographic characteristics such as education level and adherence with glaucoma medications. Approximately, two-thirds of patients in this study were in moderate or severe stages of glaucoma. However, no significant relationship was found between the disease severity and the patients' adherence. Moreover, although the rate of nonadherence was increased in those with longer duration of disease, the relationship between disease duration and adherence was not statistically significant. Tamrat et al. also reported lower levels of adherence to medications in patients with more advanced glaucoma (11). Perhaps patients with advanced and long-term disease are disappointed with the effects of medications, which reduced their adherence to medications. The present study revealed a significant relationship between intervals of medical visits and adherence to medications. This finding was consistent with results of Tamrat et al. (11). Due to the positive effects of regular medical visits on patients' adherence, patients must be encouraged to do regular follow-up visits to the ophthalmology clinic or physician's office. Then, physicians cannot only monitor the disease progress, but also can re-train patients on the crucial importance of strict compliance with medication plans. The present study showed that patients' lack of knowledge about disease and forgetting the medications were the most common causes of their nonadherence to medications. Forgetting the medications was also a barrier to patients' adherence to glaucoma treatments in studies conducted by Heidari et al. (13), Sleath et al. (16), and Mowatt et al. (20) in an exploratory study of factors influencing glaucoma treatment adherence, Stryker and Beck reported that, while forgetting medications was the most common problem experienced by patients, teaching patients about the entity of the disease, physicians' clear and understandable responses to the patients questions, and informing the patients about the crucial importance of strict adherence to medical advices were among the most important factors affecting patients' adherence (23). Knowledge deficit is a common and important 
nursing diagnosis in patients with all diseases and especially in chronic diseases (24) such as glaucoma and, thus, alarms nurses and physician about the need for patient education. Educating the patients on the entity of glaucoma and its complications, especially the danger of permanent loss of vision, can encourage patients to not only adhere to the medical plan but also to perform regular visits with their concerned doctors. In this study, we determined a wide range of factors affecting patients' adherence to glaucoma medications. Logistic regression model showed that large number of the medications, problems in scheduling times for medical visits, side effects of glaucoma medications, difficulties in travel to and from the doctor's office, forgetting the medications, having difficulties in using eye drops, and impatience for presentation of the drugs' effects, could predict $89 \%$ of variance in patients' adherence to glaucoma medications. Although we tried to interview all patients in a private and comfortable setting, the patients' responses might be affected by their psychological condition that could not be fully controlled by the researchers.

\section{Conclusions}

About two-thirds of patients with open-angle glaucoma did not adhere to their own medication usage. Excessive number of the medications, problem in scheduling times for medical visits, side effects of glaucoma medications, difficulties in travel to and from the doctor's office, forgetting the medications, having difficulties in using eye drops, and impatience were among the most important factors affecting patients' adherence to glaucoma medications. All these factors are modifiable, and, if appropriately modified, the patients' adherence might significantly be improved. Besides physicians, nurses can play an important role in appropriate and frequent patient education on the lifelong nature of the disease and the importance of keeping with medication plans. Moreover, as traveling and forgetting were among the common barriers to adherence, the ophthalmology clinics are suggested to assign particular nurses for periodic home visits and telephone contact with patients with glaucoma, to monitor their medication adherence behaviors, retrain them on the nature of the disease and its complications, medication plan, and to answer the patients' questions. Then the effects of these strategies on patients' adherence can be studied.

\section{Acknowledgments:}

The author thanks for all patients who participated in this study. We are also thankful of the authorities and ophthalmologists of the Matini Hospital for their co-operation. This study was supported by Kashan University of Medical Science, Kashan, Iran (grant number 9471).

\section{Conflict of Interest:}

There is no conflict of interest to be declared.

\section{Authors' contributions:}

Both authors contributed to this project and article equally. Both authors read and approved the final manuscript.

\section{References:}

1) American Academy of ophthalmology. Primary open-angle glaucoma-Europe. 2013. Available from: http://www.aao.org/topic-detail/primary-openangle-glaucoma--europe

2) Lu VH, Goldberg I, Lu CY. Use of glaucoma medications: state of the science and directions for observational research. Am J Ophthalmol. 2010; 150(4): 569-74.e9. doi: 10.1016/j.ajo.2010.05.005. PMID: 20678750.

3) Amini H, Javadi M, Pakravan M, Karimian F, Velaei N, Rezaei A, et al. The prevalence of glaucoma in people over 40 years living in Tehran. Bina J Ophthalmol. 2003; 9(1): 3-13.

4) Masumi R, Masumiganjgah A, Ojaghi H, Banazadeh E. Prevalence of visual impairment in adult's patient over 40 years old in Alavi hospital during 2005-6. J Ardabil Univ Med Sci. 2012; 12(2): 166-72.

5) Nordmann JP, Denis P, Vigneux M, Trudeau E, Guillemin I, Berdeaux G. Development of the conceptual framework for the Eye-Drop Satisfaction Questionnaire (EDSQ) in glaucoma using a qualitative study. BMC Health Serv Res. 2007; 7: 124. doi: 10.1186/1472-6963-7-124. PMID: 17683594, PMCID: PMC1973077.

6) Konstas AG, Maskaleris G, Gratsonidis S, Sardelli C. Compliance and viewpoint of glaucoma patients in Greece. Eye (Lond). 2000; 14 Pt 5: 752-6. doi: 10.1038/eye.2000.197. PMID: 11116698.

7) Sabate E. Adherence to long-term therapies, evidence for action: World Health Organization. 2003. Available from: http://www.who.int/chp/knowledge/publications/adherence-full-report.pdf.

8) Nordstrom BL, Friedman DS, Mozaffari E, Quigley HA, Walker AM. Persistence and adherence with topical glaucoma therapy. Am J Ophthalmol. 2005; 140(4): 598-606. doi: 10.1016/j.ajo.2005.04.051. PMID: 16226511. 
9) Schwartz GF, Quigley HA. Adherence and persistence with glaucoma therapy. Surv Ophthalmol. 2008; 53 Suppl 1: 57-68. doi: 10.1016/j.survophthal.2008.08.002. PMID: 19038625.

10) Olthoff CM, Schouten JS, van de Borne BW, Webers CA. Noncompliance with ocular hypotensive treatment in patients with glaucoma or ocular hypertension an evidence-based review. Ophthalmology. 2005; 112(6): 953-61. doi: 10.1016/j.ophtha.2004.12.035. PMID: 15885795.

11) Tamrat L, Gessesse GW, Gelaw Y. Adherence to topical glaucoma medications in Ethiopian patients. Middle East Afr J Ophthalmol. 2015; 22(1): 59-63. doi: 10.4103/0974-9233.148350. PMID: 25624675, PMCID: PMC4302478.

12) Ung C, Zhang E, Alfaro T, Murakami Y, Zhang M, Seider MI, et al. Glaucoma severity and medication adherence in a county hospital population. Ophthalmology. 2013; 120(6): 1150-7. doi: 10.1016/j.ophtha.2012.11.026. PMID: 23453512, PMCID: PMC3674151.

13) Heydari F, Shenasi A, Akbari R. The continuation of treatment adherence in patients with glaucoma and glaucoma clinic Nikoukari Hospital Tabriz. Med J Tabriz Univ Med Sci. 2012; 34(5): 24-7.

14) Welge-Lussen U, Weise S, Yu AL. Assessing the adherence behavior of glaucoma patients to topical eye drops. Patient Prefer Adherence. 2014; 9: 17-23. doi: 10.2147/PPA.S69943. PMID: 25565780, PMCID: PMC4274150.

15) $\mathrm{Yu} \mathrm{AL}$, Weise $\mathrm{S}$, Welge-Lussen U. Intensity of side effects of topical glaucoma medication and its influence on adherence behavior in patients with glaucoma. Clin Ophthalmol. 2014; 8: 1221-6. doi: 10.2147/OPTH.S62494. PMID: 25061268, PMCID: PMC4085302.

16) Sleath B, Blalock SJ, Covert D, Stone J, Skinner AC, Muir KW, et al. Patient race, reported problems in using glaucoma medications, and adherence. ISRN Ophthalmol. 2012; 2012: 902819. doi: 10.5402/2012/902819. PMID: 24558595, PMCID: PMC3914256.

17) Morisky DE, Green LW, Levine DM. Concurrent and predictive validity of a self-reported measure of medication adherence. Med Care. 1986; 24(1): 67-74. PMID: 3945130.

18) American Academy of Ophthalmology. Basic and clinical science cours. 10nd, editor. Singapore, Roy Wilson. 2012.

19) Newman-Casey PA, Robin AL, Blachley T, Farris K, Heisler M, Resnicow K, et al. The most common barriers to glaucoma medication adherence: a cross-sectional survey. Ophthalmology. 2015; 122(7): 130816. doi: 10.1016/j.ophtha.2015.03.026. PMID: 25912144, PMCID: PMC4485580.

20) Mowatt L, Nelson-Imoru J, Gordon-Strachan G. Glaucoma medication compliance issues in a Jamaican hospital eye clinic. West Indian Med J. 2011; 60(5): 541-7. PMID: 22519230.

21) Abu Hussein NB, Eissa IM, Abdel-Kader AA. Analysis of factors affecting patients'compliance to topical antiglaucoma medications in Egypt as a developing country model. J Ophthalmol. 2015; 2015: 234157. doi: 10.1155/2015/234157. PMID: 26167292, PMCID: PMC4488247.

22) Cook PF, Schmiege SJ, Mansberger SL, Kammer J, Fitzgerald T, Kahook MY. Predictors of adherence to glaucoma treatment in a multisite study. Ann Behav Med. 2015; 49(1): 29-39. doi: 10.1007/s12160-0149641-8. PMID: 25248302, PMCID: PMC4336606.

23) Stryker JE, Beck AD, Primo SA, Echt KV, Bundy L, Pretorius GC, et al. An exploratory study of factors influencing glaucoma treatment adherence. J Glaucoma. 2010; 19(1): 66-72. doi: 10.1097/IJG.0b013e31819c4679. PMID: 20075676, PMCID: PMC2808197.

24) Hinkle J, Cheever K. Study Guide for Brunner \& Suddarth's Textbook of Medical-Surgical Nursing. 13th, editor. China: Lisa McAllister. 2014. 